\title{
Does multiple injection sclerotherapy have a role in the long-term management of oesophageal varices?
}

\author{
H. D. SINNETT* \\ F.R.C.S \\ I. M. MURRAY-LYON \\ B.Sc., M.D., F.R.C.P., F.R.C.P. (Edin.) \\ K. W. REYNOLDS \\ M.S., F.R.C.S. \\ A. G. JOHNSON† \\ M.Chir., F.R.C.S. \\ Departments of Surgery \& Gastroenterology, Charing Cross Hospital, London W6
}

\begin{abstract}
Summary
Sixty-nine cirrhotic patients were treated by injection sclerotherapy for bleeding oesophageal varices, with an emergency hospital mortality, from all causes, of 29\%. The treatment of 35 of these continued with elective, long-term injections alone: 9 have so far survived more than 3 years, the longest being 5 years 4 months. The risk factor for rebleeding per patient month was 0.03 and, with its minimal complications, long-term sclerotherapy can be recommended as an alternative to portasystemic shunts for all grades of liver disease.
\end{abstract}

\section{Introduction}

The treatment of bleeding oesophageal varices poses two therapeutic problems: the management of the acute variceal haemorrhage and prevention of recurrent bleeding.

Although injection sclerotherapy has been found to be effective in stopping bleeding in an emergency (Novis et al., 1976; Crafoord and Frenckner, 1939; Macbeth, 1955; Johnston and Rodgers, 1973; Terblanche, Northover and Bornmann, 1979), its use in the long-term management of patients with recurrent variceal haemorrhage is still debatable, especially when compared with portasystemic shunts. Prospective randomized trials of portacaval shunting (Reuff et al., 1976) showed no significant prolongation of survival in shunted groups when compared with medically treated controls. Although initial results found that the Warren distal spleno-renal shunt minimized the incidence of postoperative encephalopathy (Rikkers et al., 1978), recent reports have shed doubt on its selectivity (Smith, 1979) and the shunt

Present addresses: *St Bartholomew's Hospital, London ECl. †University Surgical Unit, Royal Hallamshire Hospital, Sheffield S10 2JF. occlusion rate overall is about $10 \%$ (Mehigan, Zuidema and Cameron, 1980).

Repeated injections have also been used to sclerose varices. Terblanche et al. (1981) and Clark et al. (1980) have recently shown that although injection sclerotherapy in the short term does not eliminate further episodes of haemorrhage, the frequency of rebleeding is reduced when compared with noninjected controls.

We have reviewed our experience of patients presenting with variceal haemorrhage, treated by repeated injection sclerotherapy only, during a longterm follow-up of up to 5 years.

\section{Patient selection and methods}

A total of 69 patients with haemorrhage from oesophageal varices secondary to cirrhosis have been treated by emergency injection sclerotherapy using general anaesthesia, a rigid Negus oesophagoscope and intravascular injection of ethanolamine (Johnson, 1977). Fifty-nine of these had at least one emergency injection (within $24 \mathrm{hr}$ of a bleed), the remaining 10 having sclerotherapy as an elective procedure, from $48 \mathrm{hr}$ to 1 week after the bleeding had stopped, but during the same admission. Six patients required further operative procedures due to persistent bleeding: there were 3 Boerema-Crile procedures and 3 oesophageal transections using the stapling gun. Because of long-term follow-up problems, but after bleeding had been controlled by emergency sclerotherapy, 3 further gun transections and 12 elective shunts were performed ( 8 Grade $A$ ).

Thirty-five of the 59 patients treated by at least one emergency injection, who survived for 6 weeks or longer after the initial bleed were then treated by repeated injection sclerotherapy if they were able to attend for regular, closely supervised follow-up, 
including elective endoscopy, or if they were considered unfit for shunting. Elective injections were performed at each endoscopy until all the varices were thrombosed and subsequently if further varices developed during the follow-up period.

The aetiology of the varices varied, with 29 cases of cryptogenic cirrhosis, 1 primary biliary cirrhosis, 1 schistosomiasis, 11 chronic active hepatitis and 27 with alcoholic cirrhosis. The ages ranged from 11 to 74 years, with $64 \%$ being in the $60-70$ age-group.

Using a modified Child's classification (Pugh et al., 1973), of the 69 patients treated there were 33 Grade A, 20 Grade B and 16 Grade C.

\section{Results}

Sixty-two patients were available for study because 7, after receiving emergency injection treatment, moved away from the area and were lost to followup. Our results of emergency injection sclerotherapy are similar to those from other centres (Table 1); the slightly higher mortality is because we have not included those with non-cirrhotic portal hypertension.

Of the 35 patients on long-term sclerotherapy treatment only 18 had alcoholic cirrhosis. There were 12 with a modified Child's Grade A (7 alcoholic), 12 Grade B (5 alcoholic) and 11 Grade C (6 alcoholic), the grading being given at the time of emergency admission. All patients were advised to stop drinking alcohol, in the hope that abstinence might increase the subsequent survival, but biochemical tests, such as urinary alcohol levels, were not used to detect compliance.
The long-term follow-up results of these 35 pa- $\varrho$ tients are given in Table 2 . At present there are $11 \frac{3}{\$}$ patients who have survived for 2 years and longer, $\varrho$

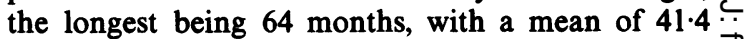
months ( 13.4 s.e. mean). Of these, there were 7 Grade $\overrightarrow{\vec{F}}$ A, 1 Grade B and 3 Grade C. Figure 1 shows the $-\overrightarrow{0}$ treatment schedule. A total of 74 injections was performed, 33 as emergency and 41 elective.

For the 35 patients, the risk factor for bleeding per $\vec{\nabla}$ patient month (the total number of bleeds divided by $\propto$ the total length of follow-up in months) was 0.03 .

\section{Complications}

There were no deaths following elective injections. Retrosternal discomfort, lasting for 16-24 hr was or experienced by the majority of patients following $\infty$ injection and Sengstaken intubation. A stricture at $\underset{+}{\infty}$ the injection site at the lower end of the oesophagus $\vec{\omega}$ occurred in 2 cases, one after 4 injections, the other $\subseteq$ after 12. So far, neither has needed dilatation.

\section{Discussion}

Although this is not a controlled trial, it \& encouraging to see that long-term repeated injection sclerotherapy has played a part in enabling $\bar{\theta}$ patients to survive a minimum of 24 months, and 9 for 36 months. These compare favourably with the published figures for portacaval shunts. Rikkers et al. $\frac{\circ}{\perp}$ (1978), found in a trial of non-emergency shunts,

TABLE 1. Comparison of results (\%) of emergency treatment in three centres

\begin{tabular}{lccc}
\hline & $\begin{array}{c}\text { Charing Cross* } \\
(n=59)\end{array}$ & $\begin{array}{c}\text { Belfast** } \\
(n=117)\end{array}$ & $\begin{array}{c}\text { Cape Town*** } \\
(n=66)\end{array}$ \\
\hline $\begin{array}{c}\text { Definitive control } \\
\text { per admission } \\
\begin{array}{c}\text { Hospital admission } \\
\text { mortality }\end{array}\end{array}$ & 89 & 93 & 95 \\
$\begin{array}{c}\text { Proportion of patients } \\
\text { with extra-hepatic } \\
\text { blocks (non-cirrhotic) }\end{array}$ & 29 & 18 & 28 \\
\hline
\end{tabular}

*This study; **Johnston and Rodgers (1973); ***Terblanche et al. (1979).

TABLE 2. Follow-up of 35 patients treated by injection only

\begin{tabular}{lccccc}
\hline & No. of patients & Deaths & $\begin{array}{c}\text { Mean Mortality } \\
\text { Time }\end{array}$ & Causes of Death & $\begin{array}{c}\text { Nos of } \\
\text { Rebleeds }\end{array}$ \\
\hline 6 weeks-12 months & 19 & 4 & $2 \cdot 5$ & $\begin{array}{l}\text { Pancreatitis } \\
\text { Liver failure } \\
\text { Rec. bleeding } \\
\text { Not determined } \\
\text { Not determined } \\
\text { 1 CVA }\end{array}$ & 22 \\
24 months-24 months & 5 & 2 & 13.5 & 5 & 0 \\
\hline
\end{tabular}




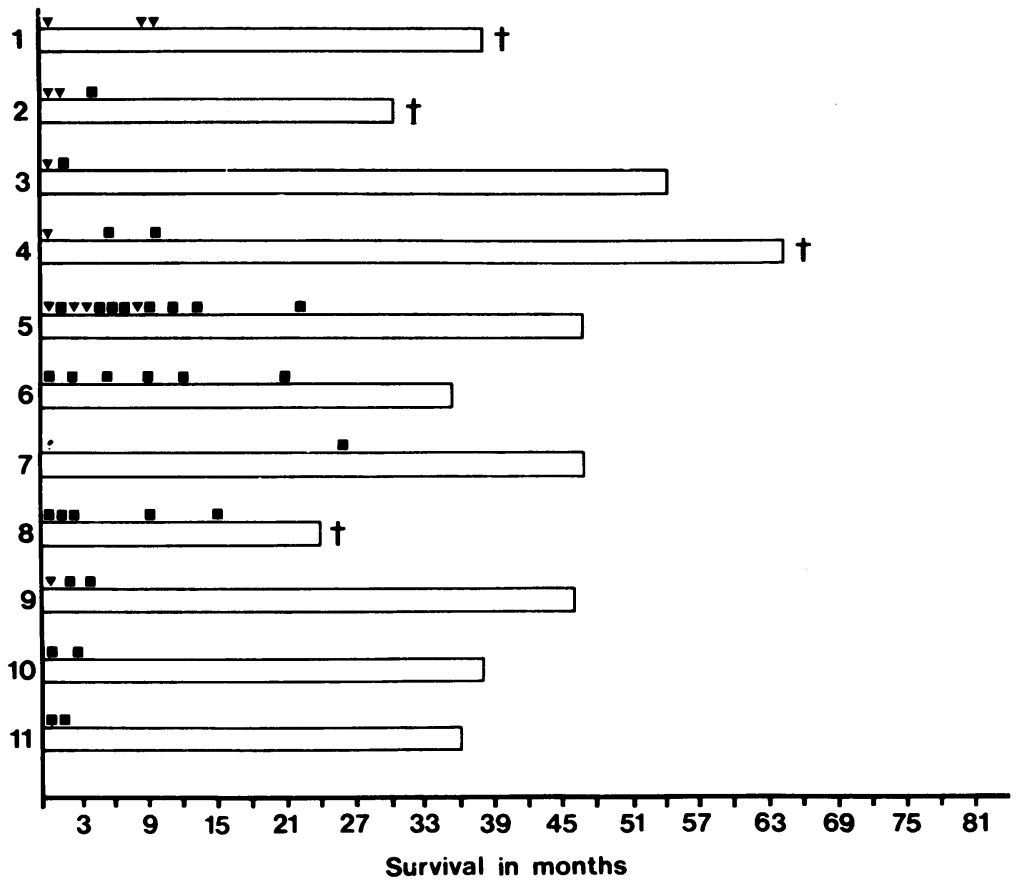

FIG. 1. Treatment schedule for 11 patients surviving for longer than 24 months with injection sclerotherapy only.

elective; $\boldsymbol{\nabla}$, emergency

with a maximum follow up of 6 years, an overall mortality of $38 \%$ of 26 selective shunts ( $12 \%$ operative mortality) and $28 \%$ of 29 non-selective shunts (10\% operative mortality). The mean time of the fatalities was 26.7 months and 12.8 months respectively. The comparative figure from our study with a $5 \frac{1}{2}$ year follow-up is $25 \%$ of 35 patients at a mean time of 20 months. (The long-term sclerotherapy patients, like the shunt patients, have already survived the initial bleed). As patients chosen for shunts had a better average Child's grading than the sclerotherapy patients, it is clear that sclerotherapy gives as good, if not better survival than sither form of shunting.

The best results in patients selected for distal spleno-renal shunting give a risk factor for rebleeding per patient month of 0.002 for a 1-51 month followup (Hutson et al., 1976). Our risk factor of 0.03 over a follow-up period up to 64 months for patients in Grades A, B and C, compares favourably with Clark's figures over a shorter follow-up period (25 months).

Although preliminary trials with injection sclerotherapy are encouraging, its true value is difficult to assess, because there is, as yet, no agreed classification of the severity of varices, and the aetiology of the cirrhosis varies considerably from place to place. Controlled trials against other forms of treatment present problems of patient selection. For example, a trial against distal spleno-renal shunting could only include those with good liver function and even the encouraging results with beta-blockers are so far in selected good risk patients (Lebrec et al., 1981).

We conclude that recurrent long-term sclerotherapy with its very low mortality from elective injection, is a valid alternative to shunting. For those with poor liver function, sclerotherapy is the best method available.

\section{References}

Clark, A.W., Westaby, D., Silk, D.B.A., Dawson, J.L., MaCDougall, B.R.D., Mitchell, K.J., Strunin, L. \& Williams, R. (1980) Prospective controlled trial of injection sclerotherapy in patients with cirrhosis and recent variceal haemorrhage. Lancet, ii, 552.

Crafoord, C. \& Frenchner, P. (1939). Surgical treatment of varicose veins of the oesophagus. Acta Otolaryngologia, Stockholm, 27, 422.

Hutson, D.G., Pereiras, R., ZePPa, R., LeVi, J.U., SChiff, E.R. \& FIND, P. (1976) The fate of esophageal varices following selective distal splenorenal shunt. Annals of Surgery, 183, 496.

JoHNSON, A.G. (1977) Injection sclerotherapy in the emergency and elective treatment of oesophageal varices. Annals of the Royal College of Surgeons of England, 59, 497.

JOHNSTON, G.W. \& RODGERS, H.W. (1973) A review of 15 years' experience in the use of sclerotherapy in the control of acute haemorrhage from oesophageal varices. British Journal of Surgery, 60, 797.

Lebrec, D., Poynard, T., Hillon, P. \& Benhamou, J-P. (1981) Propranolol for prevention of recurrent gastrointestinal bleeding 
in patients with cirrhosis. New England Journal of Medicine, 305, 1371.

MACBETH, R. (1955). Treatment of oesophageal varices in portal hypertension by means of sclerosing injection. British Medical Journal, 2, 877.

Mehigan, D.G., Zuidema, G.D. \& Cameron, J.L. (1980) The incidence of shunt occlusion following portasystemic compression. Surgery, Gynecology and Obstetrics, 150, 661.

Novis, B.H., DuYs, P., Barbezat, G.O., Clain, J., Bank, S. \& TERBLANCHE, J. (1976) Fibreoptic endoscopy and the use of the Sengstaken tube in acute gastrointestinal haemorrhage in patients with portal hypertension and varices. Gut, 17, 258

Pugh, R.N.H., Murray-Lyon, I.M., Dawson, J.L., Pietroni, M.C. \& Williams, R. (1973) Transection of the oesophagus for bleeding oesophageal varices. British Journal of Surgery, 60, 646.
Reuff, B., Prandi, D., Degos, F., Degos, J-D., Maillard, J.N., ఏ

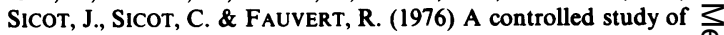
therapeutic portacaval shunt in alcoholic cirrhosis. Lancet, i, 655. Ф RikKeRS, L.F., Rudman, D., Galambos, J.T., Fulenwider, T., Millikan, W.J., Kutner, M., Smith, R.B., Salaman, A.A., JONES, P.J. \& WARREN, W.D. (1978) A randomised controlled trial of the distal spleno-renal shunt. Annals of Surgery, 188, 271. SMITH, G.W. (1979) The distal splenorenal shunt. Surgery, 86, 774. Terblanche, J., Northover, J.M.A., BornmanN, P. (1979) A prospective evaluation of injection sclerotherapy in the treatment of acute bleeding from oesophageal varices. Surgery, 85, 239.

Terblanche, J., YAKOOB, H.I., BornmanN, P.C., STIEgman, G.V., @ Bane, R., Jonker, M., Wright, J. \& KIRSCH, R. (1981) Acute ๗ֶ) bleeding varices: A 5 year prospective evaluation of tamponade and sclerotherapy. Annals of Surgery, 194, 521. 